\title{
Determinants of Online Purchasing Behavior in Nanggroe Aceh Darussalam
}

\author{
Fifi Yusmita, Nik Kamariah Nik Mat", Mulyagus Usman Muhammad, Yuhainis Mohd Yusoff, \\ Fitrisal azhar, Saeed Behjati
}

Othman Yeop Abdullah Graduate School of Business, Universiti Utara Malaysia, Sintok, 06010, Kedah Malaysia

\begin{abstract}
This study aims at identifying the determinants of online purchasing behavior (OP), vis-a vis, attitude (A), unauthorized secondary use $(\mathrm{U})$, internet trustworthiness $(\mathrm{T})$, normative structure $(\mathrm{N})$, and perceived behavior control $(\mathrm{P})$. Each variable is measured using an adapted instrument with 7-point interval scale. Using primary data collection method, 200 questionnaires were distributed to online purchasing customers. This study managed to collect 147 completed questionnaires (73.5\%). The data were analyzed using Structural Equation Modeling (SEM. Confirmatory factor analysis of measurement models indicate adequate goodness of fit after a few items were eliminated through modification indices verifications. Goodness of fit for the revised structural model also shows adequate fit thus meeting all requirements in terms of cmindf ratio:1,238; p-value: 0.098; GFI: 0.932; and rmsea;0.040. In the end, this study has established three direct causal effects: (1) attitude and online purchasing behavior; (2) unauthorized secondary use and online purchasing behavior; (3) normative structure and online purchasing behavior; (4) perceived behavior control and online purchasing behavior; (5) Internet trustworthiness and online purchasing behavior. The findings show that perceived behavior control $(\beta=.582, \mathrm{CR}=6.656$ $\mathrm{p}=0.000)$, attitude $(\beta=-.307, \mathrm{CR}=-2.781, \mathrm{p}=0.005)$ and internet trustworthiness $(\beta=.527, \mathrm{CR}=4.454, \mathrm{p}=0.000)$ have significant relationship with online purchasing behavior while normative structure and unauthorized secondary use have insignificant relationship with online purchasing behavior. The findings are discussed in regards of online customers and its implications to online shopping.
\end{abstract}

Keywords Online Purchasing Behavior, Normative Structure, Perceived Behavior Control, Attitude, Internet Trustworthiness, Unauthorized Secondary Use

\section{Introduction}

Online purchasing behavior is a reasonably new phenomenon. Every year, the number of people who sort out online purchasing is incessantly increasing. It shows that online transaction is growing rapidly and more studies are needed to clarify the factors influencing it, among others namely attitude, unauthorized secondary use, internet trustworthiness, normative structure and perceived behavior control. With reference to a survey on 3156 people in China, India, Malaysia, Taiwan, Indonesia, and Thailand over their online shopping habit and factors motivating them, it was found that they spend $24 \%$ of expenditures for online shopping. In addition, online shopping behavior has become a life style for most of the people in the world. In general, online consumers prefer to purchase goods, services, and information online[1]. Online purchasing has unique features that differs it from the traditional purchasing process,

* Corresponding author:

drnikuum@gmail.com (Nik Kamariah Nik Mat)

Published online at http://journal.sapub.org/economics

Copyright (C 2012 Scientific \& Academic Publishing. All Rights Reserved particularly with regards to its social context[2]. Besides the promising trend, little is known about how particular variables influence consumers' spending habits online.

Accordingly, the purpose of this study is to clarify the understanding of online purchasing behavior model, determined by variables particularly (1) attitude, (2) unauthorized secondary use, (3) internet trustworthiness, (4) normative structure, and (5) perceived behavior control. In order to justify the model, this study compares five alternative models for predicting online purchasing behavior. These alternative models have been utilized for better understanding the relationships among our proposed constructs[3].

Therefore, the aim of this study is to develop and test alternative models, which can assist in the comprehensive understanding of online purchasing behavior from the theoretical perspective. Although it is evident that a few studies have investigated multiple direct links among the five variables, there has no investigation been carried out on their level of influence on online purchasing behavior and its effects of all five alternative models. Hence, this study proposes to ascertain if the five alternative constructs could address their true relationships in selecting the best model for 
online purchasing behavior model.

Finally, the remainder of this paper is organized as follows. The first two sections provide the underpinning theoretical background for five alternative models that examine the effect of key of determinants on online purchasing behavior. The third section describes the methodological approach and provides the justification to authenticate the proposed conceptual model. Then, results from SEM are presented, followed by discussion of empirical findings which lead to some practical and theoretical implications. Finally, limitations for this study and area for future research are discussed.

\section{Literature Review}

This section reviews related research on online purchasing behavior of customers in Acheh. To support the background for this topic, reviews on related studies is very important for gaining insight into the real situation of online purchasing behavior.

\subsection{Online Purchasing Behavior}

Online purchasing behavior refers to the process of purchasing products, services, and information via the Internet. In a typical online shopping process, when the potential online consumers need some merchandise or service or their related information, they go to the Internet and search for intended information; then they evaluate the alternatives and choose the one that best fit their criteria for gathering the felt need. Subsequently,[4] states that many consumers resist making purchases via the Internet because they are concerned about the privacy of the personal information. Finally, after they found merchandise or service or information which best fit them and they feel secured that website, then they will do the transaction.

The research framework is based on the Theory of Reasoned Action (TRA) which states that an individual's performance of a certain behavior is determined by his or her intent to perform that behavior. Besides, Theory of Planned Behavior (TPB) [5], which is an extension of the TRA[6] also supports online purchasing behavior. Recently, TRA and TPB have also been the basis for several studies of Internet purchasing behavior[7],[8].

In a related study, Susskind and Stefanone (2010) found that the transactions on the Internet are negatively related to consumers' on-line purchasing of goods and services. This result is opposite with previous study which found that online purchasing behavior is part of transactions on the Internet. This creates a gap for further study in this particular area.

\subsection{Attitude}

In order to achieve a better understanding of the online shopping phenomena, we should be concerned about potential variables that might influence the decision to purchase merchandise and services online. In this regard, the TRA has been widely used to explain the consumer decision-making process. The theory postulates that behavioral intention is the function of two components: attitude toward a behavior and subjective norm; which are direct determinants of intention to perform a behavior.

Generally, it is difficult to find a comprehensive definition of attitude, but most researchers agree that attitude is considered to be a property of an individual personality. Attitude is reinforced by beliefs or perceptions and these feelings will lead to particular types of behavior that form the action. Related to this study, attitude plays a role in the process of online purchasing behavior. In conjunction, Foxall et al.,[10] believe that attitude is affected by past behavior and represents the future behavior. Also, attitude is the evaluation of performing a particular behavior involving the attitude object, such as buying products[11]. These statement clearly state that attitude has a relationship with behavior. Therefore, consumer's attitude is potentially related with online purchasing behavior.

There have been intensive studies of online shopping attitudes and behavior in the literatures. Attitude towards a behavior is either a positive or negative factor of performing that behavior[12]. Besides, George[7] found a positive relationship between attitude and online purchasing behavior. These previous studies have all made important contributions to our understanding of the dynamics of online shopping behavior. However, there is still a lack of consistent understanding on the impact of relevant factors of online purchasing behavior related to independent and dependent variables. On the other hand, Bellman et al.,[13], observe the relationship among demographics, personal characteristics, and attitudes towards online shopping. These authors found that people who have a more "wired lifestyle" and more time-constraint tend to purchase online more frequently. Moreover, Hasan[14] states that attitudes are formed over time as people gain experience with the behavior or receive knowledge about the object from other sources.

H1: There is a positive relationship between attitude and online purchasing behavior

\subsection{Unauthorized Secondary Use}

Unauthorized secondary use is a part of consumer's privacy concern to get the personal information[15]. Verhagen et al.,[16] mention that unauthorized secondary use are an individual's concerns about whether data are collected for one purpose may be used for another purpose. George[4] stated that unauthorized secondary use have insignificant relationship with online purchasing behavior. However, Carter et al.[17] argue that unauthorized secondary use has significant impact on getting information. Based on the addressed definitions, this study hypothesizes that as consumers who want to do an online purchasing to get some information, they will use their personal information to achieve it. 
H2: There is a negative relationship between unauthorized secondary use and online purchasing behavior

\subsection{Internet Thrust Worthiness}

Trust is particularly important in online shopping[18],[19]. It has been demonstrated that trusting beliefs positively influence online consumers purchase intentions[16], [20],[21]. The definition of trust proposed by Mayer et al.[22] is the most widely accepted. It runs as "... the willingness of a party to be vulnerable to the actions of another party based on the expectation that the other will perform a particular action important to the trust or, irrespective of the ability to monitor or control that other party". This leads to the formation of hypothesis $\mathrm{H} 3$.

H3: There is a positive relationship between Internet trust worthiness and Online purchasing behavior

\subsection{Normative Structure}

Normative structure is the belief about what important others think about the behavior in question, which should directly influence people's subjective norms, or perceptions of the social pressure to comply with expectations about appealing behavior. The previous studies argue that normative structure have direct relationship with online purchasing behavior[4],[23],[24]. This forms the hypothesis H4.

H4: There is a positive relationship between normative structure and online purchasing behavior

\subsection{Perceived Behavior Control}

Based on TPB, perceived behavior control is defined as an individual's confidence that he or she is capable of performing the behavior[5]. It has two aspects of perceived behavior control; firstly, how much a person has the control over the behavior, while the second is how confident a person feels about being able to perform or not perform the behavior. The more the control an individual feels about making online purchase, the more likely he or she will be to do so. In this study, perceived behavioral control is the ability to purchase online. However, Kwong and Park[25] found different results. They found the insignificant effects of perceived behavioral control on behavior. The inconsistent results are needed to test again, for getting the comprehensive approaches, making the hypothesis $\mathrm{H} 5$ is necessary.

H5: There is a positive relationship between perceived behavior control and online purchasing behavior

\section{Methodology}

\subsection{Research Framework}

The following is the diagram of the research design to be used in this study:

This study attempts to determine the online purchasing behavior predictors as elaborate in Figure 1. The research framework reveals that online purchasing behavior have a direct effect on attitude, unauthorized secondary use, internet trustworthiness, normative structure, and perceived behavior control.

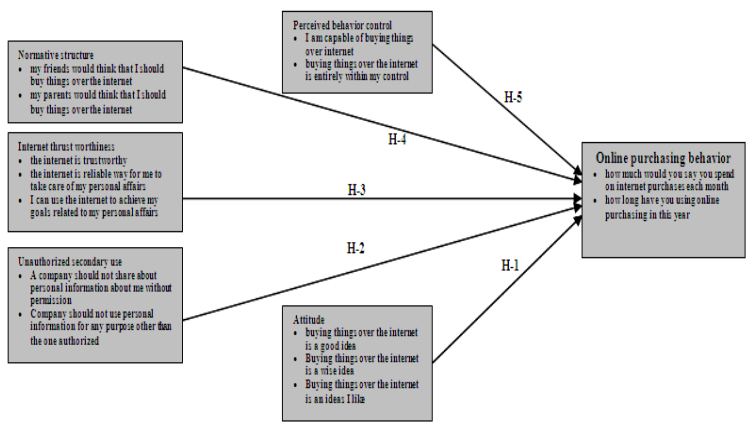

Figure 1. Research frmework

Questionnaires were distributed to 200 respondents (students of Syiah Kuala University, Acheh- Indonesia) using convenience sampling, in which 147 were completed and returned $(73.5 \%)$. Each student was given a self-administered questionnaire containing sociodemograph ic information, including age, gender, duration of internet experience, own a PC, and frequency of purchase online. The rest parts of the questionnaire focus on items that could be used to construct the latent variables. These were generated from previous research papers and were modified to fit the context of online purchasing behavior. Lastly, the questionnaires were collected immediately after the students had completed it.

In detail, the questionnaire contains 14 items that are categorized into 6 variables, specifically 1 dependent variable (online purchasing behavior-2 items) and 5 independent variables (attitude-3 items; unauthorized secondary use-2 items; internet trustworthiness-3 items; normative structure-2 items; and perceived behavior control-2 items) after that the data were analyzed using SEM. Exploratory factor analysis (EFA) and Confirmatory Factor Analysis (CFA) were conducted for all variables individually to make sure that all items are free from high correlation relationship with an ultimate aim to achieve the model fit.

In addition, by using SEM an explanation can be given rather than a description of online purchasing behavior and the relationship between attitude and online purchasing behavior; unauthorized secondary use and online purchasing behavior; normative structure and online purchasing behavior; perceived behavior control and online purchasing behavior; and the latest, Internet trustworthiness and online purchasing behavior. SEM allows for multiple simultaneous directions of causality, and distinguishes the direct effect and the indirect effect as well as the total effect of an explanatory variable on each dependent variable[26].

\section{Findings}

\subsection{Socio Demography}


The sample (Table 1) consists of 69 (46.9\%) male and 78 (53.1\%) female, of ages between 17 and 25 . All participants have internet access and who mostly use at least one hour per week. Additionally, more than half of the students own a PC $(89.1 \%)$, and $(81.0 \%)$ have used the internet for at least7 years. Surprisingly, 69 of them have never purchase online.

Table1. Socio Démographics

\begin{tabular}{|c|c|c|}
\hline & Frequency & $\%$ \\
\hline Gender & & \\
Male & 67 & 46.9 \\
Female & 78 & 53.1 \\
Ages & & \\
17-19 & 37 & 25.7 \\
$20-22$ & 90 & 61.2 \\
$23-25$ & 20 & 13.6 \\
Duration use internet & 117 & 79.5 \\
At least One hour per day & 30 & 20.4 \\
One hour per week & & \\
Own PC & 131 & 89.1 \\
Have own PC & 16 & 10.8 \\
Don't Have own PC & & \\
Duration used internet & 22 & 14.9 \\
1-3 years & 45 & 30.6 \\
4-6 years & 54.4 \\
7 years and above & & \\
& & \\
\hline
\end{tabular}

\subsection{Hypothesis Results}

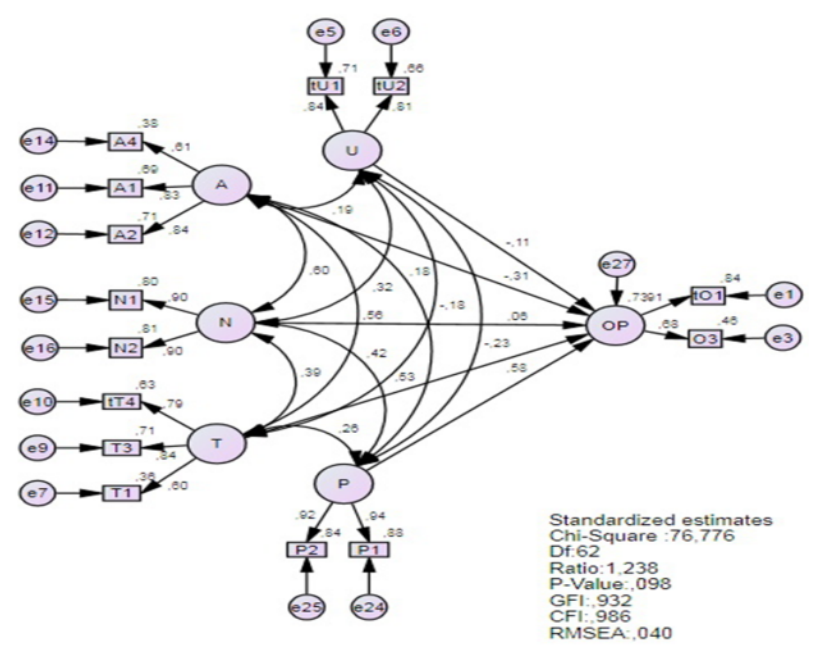

Figure.2 Revised model

From the analysis, a revised model was achieved which possessed adequate goodness of fit with values for ratio as 1.238, P-Value as 0.098, GFI as 0.092 and RMSEA as 0.0040 (table 2 in appendix). Based on those results, this study finds that three of hypothesis are significant, for instance perceived behavior control (H5) at $\beta=0.582, \mathrm{CR}=$ 6.656, $\mathrm{p}<0.001$; attitude $(\mathrm{H} 1)$ at $\beta=-0.307, \mathrm{CR}=-2.781$ $\mathrm{p}<0.005$, and also internet trustworthiness (H3) at $\beta=0.527$, $\mathrm{CR}=4.454, \mathrm{p}<0.001$. This explains that $\mathrm{H} 1, \mathrm{H} 3$, and $\mathrm{H} 5$ have significant relationships with online purchasing behavior, however, attitude is negatively related to on-line purchasing.
This finding is supported by Susskind and Stefanone (2010). In contrast, normative structure $(\mathrm{H} 4)$ at $\beta=0.013, \mathrm{CR}=0.546$, $\mathrm{p}=0.585$; and unauthorized secondary use (H2) at $\beta=-0.102$, $\mathrm{CR}=-1.148 \mathrm{p}=0.251$ indicate insignificant relationship with online purchasing behavior (Table 2).

Table 2. Regression standardized Estimates and hypothesis results

\begin{tabular}{|l|r|r|r|r|l|}
\hline Relationship & $\begin{array}{r}\text { Std esti- } \\
\text { mate }\end{array}$ & \multicolumn{1}{c|}{ S.E } & \multicolumn{1}{c|}{ C.R } & \multicolumn{1}{c|}{$P$} & $\begin{array}{l}\text { HYPOTHESIS } \\
\text { RESULTS }\end{array}$ \\
\hline - Attitude $\rightarrow$ online purchasing behavior &. .307 & .026 & -2.781 & .005 & Supported \\
- Unauthorized secondary use $\rightarrow$ online & -.108 & .089 & -1.148 & .251 & Not Supported \\
purchasing behavior & .527 & .041 & 4.454 & $* * *$ & Supported \\
- Internet thrust worthiness $\rightarrow$ online \\
$\begin{array}{l}\text { purchasing behavior } \\
\text { - Normative structure } \rightarrow \text { online pur- } \\
\text { chasing behavior }\end{array}$ \\
$\begin{array}{l}\text { perceived behavior control } \rightarrow \text { online } \\
\text { purchasing behavior }\end{array}$
\end{tabular}

\section{Conclusions}

Generally, females are more interested on online purchasing than male. For most of the educated people, online shopping has become a behavior life style in University. Commonly, they use their own PC to do the online purchasing. The possibilities of doing through internet are influenced by personals factors such as attitude, internet trustworthiness, and perceived behavior control[4],[19],[24]. On the other hand, normative structure and unauthorized secondary use have insignificant relationship on online purchasing behavior. These results might be influenced of many reasons such as internet self-efficacy, easy access to internet and infrastructure. We found a contradictory result to our hypothesis when attitude is negatively related to on-line purchasing. A probable reason for this is that the respondents were university students who may not have fix income or credit cards facilities to buy on-line. Future research should extend the respondents to users with income or more matured citizens. Some other factors such as satisfaction and information privacy should also be included as new variables for the next models and also doing the same things in the different way namely qualitative approaches to get a comprehensive understanding about online purchasing behavior. Some limitations of the present study need to be acknowledged. First, the samples in this research were the students of university; however, the results are still useful since students belong to a large part of the online consumers, which makes them interesting to online shopping. Nevertheless, other populations should also be examined to confirm and expand the obtained results. The second, future research should therefore be more precise in specifying the terms e-shopping and in-store shopping. There is an important difference in buying apparel online at a website 
that does not have a physical store in contrast with websites that also possess a building or store for operations.

\section{ACKNOWLEDGEMENTS}

We would like to thank Prof Dr. Nik Kamariah Nik Mat and Sukma Pea for their helpful comments and assistance on an earlier version of this paper.

\section{REFERENCES}

[1] De Boer, L., Harink, J. and Heijboer, G. (2002) A conceptual model for assessing the impact of electronic procurement'. European Journal of purchasing and supply management vol.8 no.1 pp25-33.

[2] Weisberg,J; Te'eni,D and Arman,L (2011). Past purchase and intention to purchase in e- commerce;the mediation of social presence and trust. Internet research, vol 21 iss: 1 pp82-96 doi: 10.1108/10662241111104893.

[3] Ferrer. E and McArdle.J.J. (2003). Alternative structural models for multivariate longitudinal data analysis. Structural Equation Modelling,10:493-524.

[4] George, J. F (2004). The theory of planned behavior and internet purchasing The theory of planned behavior and Internet purchasing. Emerald Articledoi:10.1108/106622404 10542634

[5] Azjen, I. (1991), "The theory of planned behavior", Organizational behavior and human decision processes, Vol. 50, pp. 179-211.

[6] Azjen, I. and Fishbein, M. (1980), Understanding attitudes and sredicting Social behavior, Prentice-Hall, Englewood Cliffs, NJ

[7] George, J. F.(2002). Emerald Article??: Influences on the intent to make internet purchases influences on the intent to make Internet purchases, 12. doi:10.1108/106622402104225 21.

[8] Khalifa, M. and Limayem, M. (2003), "Drivers of Internet shopping", Communications of the ACM, Vol. 46 No. 12, pp. 233-9.

[9] Susskind, A. M., \& Stefanone, M. a. (2010). Internet apprehensiveness: An examination of on-line information seeking and purchasing behavior. Journal of Hospitality and Tourism Technology, 1(1), 5-29. doi:10.1108/17579881011022990

[10] Foxall, Gorden, Goldsmith, Ronald and Brown, Stephen. (1998). Consumer Psychology for Marketing, 2nd ed. United Kingdom : International Thompson Business Press.

[11] Blackwell,Roger D, (2006). Consumer behaviour: an Asia Pacific approach. Roger Blackwell...(et. al). Thompson Learning Australis, South Meulbourn,Vic,: .

[12] Azjen, I. (1985), "From intentions to actions: a theory of planned behavior", in Kuhl, J. and Beckman, J. (Eds), ActionControl: From Cognition to Behavior, Springer, Heidelberg, pp. 11-39.

[13] Bellman,S , Lohse,G.L., and Johnson, E,J (1999). Consumer buying behavior on the internet: finding from panel data. Communication of the ACM, vol.42(12) pp.32-48.

[14] Hasan,B. (2010). Exploring gender differences in online shopping attitude. Computers in Human Behavior DOI: 10.1016/j.chb.2009.12.012.

[15] Stewart, K,A and Segars,A.H (2002). An empirical Examination of the concern for information privacy instrument, Information Systems Research, Vol.13, No.1 pp36-49.

[16] Verhagen,T., Meents, S and Tan, Y. (2006), Perceived risk and trust associated with purchasing at electronic marketplaces, Serie research memoranda 0001, free university Amsterdam, Faculty of Economics, Business Administration Eonometrics.

[17] Carter, L., Mcbride, A., Carter, L., \& Mcbride, A. (2010). Agenda information privacy concerns and e-government?: a research agenda. doi:10.1108/17506161011028777.

[18] Ratnasingham, P. (1998), "The importance of trust in electronic commerce", Internet Research, Vol. 8 No. 4, pp. 313-21.

[19] Tang,Z., Hu,Y., Smith,M.D.,(2008), Gaining trust through online privacy protection: self-regulation, Mandatory Standards, or Caveat Empto, Journal of Management Information Systems Issue: Volume 24, Number 4 / Spring 2008 Pages: 153 - 173 DOI:10.2753/MIS0742-1222240406.

[20] ayawerdhana,C. (2004), The hierarchical influence of personal values on e-shopping attitude and behavior, internet research, electronic Networking Applications and Policy, Vol.14 No.2 pp.127-142.

[21] Jarpenvaa,S.L., Tractinsky, N. and Vitale,M (2000), Consumer trust in an internet store: Across- Cultural Validation', Journal of Computer Mediated Communication, Vol.1(1-2),pp. 45-71.

[22] Mayer,R.C., Davis, J.D. and Schoorman, F.D. (1995), An integrative model of organization trust, Academy of Management Review, Vol 20(3),pp 709-734.

[23] Song, J. and Zahedi, F.M. "Web Design In E-Commerce: A Theory And Empirical Analysis," Proceedings of the International Conference of Information Systems2001, 2001, pp. 205-220.

[24] Bhattacherjee, A. "Acceptance of e-commerce services: the case of electronic brokerages," IEEE Transactions on Systems, Man and Cybernetics, Part A, vol. 30, no. 4, 2000, pp. 411-420.

[25] Kwong, S.W. and Park, J. (2008), "Digital music services: consumer intention and adoption", The Service Industries Journal, Vol. 28, No. 10, pp. 1463-1481.

[26] Cao, X. and Mokhtarian, P. L. (2005). The Intended and Actual Adoption of Online Purchasing: A Brief Review of Recent Literature. Research Report UCD-ITS-RR-05-07, Institute of Transportation Studies, University of California, Davis, June. Available at http://www.its.ucdavis.edu/publicat ions/2005/UCD-ITS-RR-05-07.pdf. 